\title{
Influence of Mn on the Corrosion Behaviour of Medium Manganese Steels in a Simulated Seawater Environment
}

\author{
Guanqiao Su, Xiuhua Gao*, Linxiu Du, Dazheng Zhang, Jun Hu, Zhenguang Liu \\ The State Key Laboratory of Rolling and Automation, Northeastern University, Shenyang 110819, \\ Liaoning, P.R.China. \\ *E-mail: suhang_joe@163.com
}

doi: $10.20964 / 2016.11 .51$

Received: 13 August 2016 / Accepted: 18 September 2016 / Published: 10 October 2016

\begin{abstract}
The influence of $\mathrm{Mn}$ on the corrosion behaviour of medium manganese steels was studied by employing a laboratory accelerated corrosion test that involved cyclic wet/dry conditions in a simulated seawater environment. At different time points during the cyclic corrosion tests, the character of the rust film and the susceptibility of the tested medium manganese steels to corrosion were examined using SEM, XRD, and EPMA as well as analysis of the potential-pH diagram. The medium manganese steels exhibited lower corrosion resistance due to the enrichment of $\mathrm{MnFe}_{2} \mathrm{O}_{4}$ in the rust films. Moreover, the effect of small amounts of alloying Mo and Ni elements on medium manganese steels was discussed.
\end{abstract}

Keywords: medium manganese steel; weight loss; SEM; Pourbaix diagram; rust

\section{FULL TEXT}

(C) 2016 The Authors. Published by ESG (www.electrochemsci.org). This article is an open access article distributed under the terms and conditions of the Creative Commons Attribution license (http://creativecommons.org/licenses/by/4.0/). 